\title{
Analisa Kesalahan Trajektori dan Algoritma Solusi Invers pada Robot Lengan Berdasarkan Jaringan QACA-RBF
}

\author{
Ardiansyah Al Farouq ${ }^{1}$, Presto Fani ${ }^{2}$, Muhammad Yanuar Muhaimin ${ }^{3}$ \\ 1 Teknik Komputer, Fakultas Teknik Elektro, Institut Teknologi Telkom Surabaya; alfarouq01@gmail.com \\ 2 Teknik Elektronika, D4 Teknik Elektronika, Politeknik Elektronika Surabaya; dipres@gmail.com \\ 3 Teknik Komputer, Fakultas Teknik Elektro, Institut Teknologi Telkom Surabaya; \\ yanuardanu19@gmail.com
}

\begin{abstract}
Abstrak: Dalam rangka meningkatkan akurasi posisi dan trajektori dari robot lengan UR5, algoritma solusi invers pada robot lengan berdasarkan jaringan QACA-RBF diajukan. Desain algoritma ini menggunakan model prediksi melalui jaringan saraf dan menggunakan algoritma koloni semut kuantum untuk mengoptimalkan bobot keluarannya. Dalam memecahkan masalah ini, algoritma koloni semut kuantum memiliki presisi konvergen yang rendah dan mudah jatuh ke dalam solusi local optimal dalam algoritma solusi invers dari derajat kebebasan pada robot lengan, maka peningkatan pengukuran seperti local optimasi dan batas maksimum minimum feromon dan variasi dibutuhkan. Dengan membandingkan hasil simulasi dari hasil simulasi robot lengan UR5 dan hasil simulasi berdasarkan jaringan saraf ACA, QACA, dan RBF untuk mendapatkan posisi dan gerak trajektori pada titik ruang dengan kepresisian disetiap algoritma. Dengan skema tersebut agar dapat membuktikan kelayakan algotirma jaringan QACA-RBF.
\end{abstract}

Keywords: robot lengan; algoritma; trajektori; QACA; ACA.

\section{Pendahuluan}

Pada desain manufaktur moderen saat ini, robot lengan adalah perangkat elektromekanis terintegrasi yang sangat dibutuhkan. Robot lengan yang dibahas disini menggunakan robot lengan UR5. Pada dasar teori dinamika dan kinematika, keakuratan solusi invers adalah faktor penentu untuk akurasi dan efisiensi perencanaan trejektori pada robot lengan.

Solusi invers dari robot lengan UR5 adalah dasar dari trejektori robot lengan. Persamaan solusi invers memiliki karakteristik dimensi dan nonlinier yang tinggi, solusinya kompleks, dan sulit untuk menemukan solusi yang akurat. Solusi invers tradisional dapat secara kasar dibagi menjadi metode aljabar [1-6] dan metode geometris [7-9] sudah jarang digunakan karena hasil yang buruk. Dalam metode iteratif numerik yang lebih populer pada tahap ini [10-13], evolusi, bionik dan simulasi, jaringan saraf, dan algoritma lainnya adalah algoritma kecerdasan yang umum digunakan [14-16]. Meskipun metode ini telah mencapai hasil yang luar biasa, mereka masih tidak memuaskan dan terbatas dalam hal akurasi. Oleh sebab itu, maka perlu dieksplorasi lebih lanjut dan ditingkatkan.

Dalam algoritma kecerdasan, jaringan saraf RBF adalah algoritma yang sangat penting, yang dapat mendekati fungsi nonlinier dalam kepresisian. Beberapa peneliti telah menyadari pentingnya jaringan saraf dan menggunakannya untuk memecahkan solusi invers dari robot lengan untuk mendapatkan efek dan kepresisian yang relative ideal [17-19]. Dalam makalah ini, sebuah algoritma yang didasarkan pada jaringan QACA-RBF(peningkatan algoritma koloni semut) diusulkan untuk mengoptimalkan beban keluaran dari koloni semut kuantum yang ditingkatkan, kemudian hasil yang baik diperoleh. 


\section{Model Mekanikal Lengan UR5}

Mekanikal lengan UR5 yang digunakan memiliki enam derajat kebebasan. Permasalah forward kinematics nya telah diselesaikan dan lengan UR5 menggunakan sistem model parameter DH yang ditunjukkan pada Gambar 1[20-21].

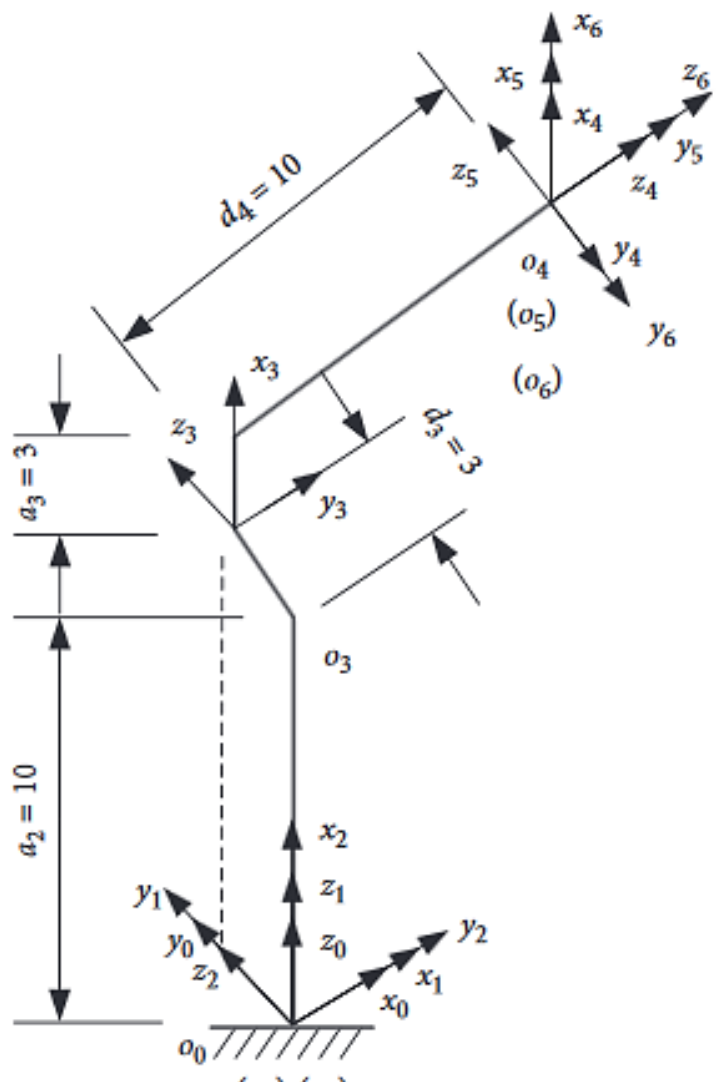

$\left(o_{1}\right)\left(o_{2}\right)$

Gambar 1: lengan UR5 menggunakan sistem model parameter DH.

Dari Gambar 1 dapat terlihat bahwa matrik konversi koordinat dari manipulator di sistem koordinat akhir joint relatif pada sistem koordinat dasarnya adalah

$$
{ }_{1}^{0} T={ }_{1}^{0} T_{2}^{1} T_{3}^{2} T_{4}^{3} T_{5}^{4} T_{6}^{5} T=\left[\begin{array}{cccc}
n_{x} & o_{x} & a_{x} & p_{x} \\
n_{y} & o_{y} & a_{y} & p_{y} \\
n_{z} & o_{z} & a_{z} & p_{z} \\
0 & 0 & 0 & 1
\end{array}\right]
$$

$\left[p_{x}, p_{y}, p_{z}\right]$ pada matrik ini merepresentasikan posisi dari bagian akhir manipulator pada sistem koordinat dasar. Sudut RPY Euler dapat dijelaskan dengan rumus berikut[21-23]:

$$
\begin{aligned}
& a=\arctan \left(a_{y}, a_{x}\right), \\
& \beta=\arctan \left(a_{x} \cos a+a_{y} \sin a, a_{z}\right), \\
& \gamma=\arctan \left(-n_{x} \sin a+n_{y} \cos a, o_{y} \cos a-o_{x} \sin a\right)
\end{aligned}
$$

Dari rumus tersebut maka dapat dilihat karena variabel dalam persamaan (1) adalah semua fungsi dari sudut joint $\theta_{i}$, posisi akhir dari $p=\left[p_{x}, p_{y}, p_{z}, \alpha, \beta, \gamma\right]$ dapat diperoleh dalam permasalahan penentuan $\theta_{i}$. 


\section{Permodelan Prediksi dari Solusi Invers Berdasarkan Jaringan QACA-RBF}

Dalam menemukan solusi invers dari robot lengan, model prediksi dari jaringan saraf dibuat. Untuk meningkatkan akurasi solusi invers, nilai bobot keluaran dioptimalkan dengan meningkatkan algoritma koloni semut kuantum, sehingga kesalahan antara keluarannya dengan keluaran aktualnya diminimalkan.

RBF adalah salah satu algoritma pembelajaran jaringan saraf. Struktur pada jaringan saraf RBF terdapat lapisan masukan, lapisan tersembunyi (hidden layer, dan lapisan keluaran.

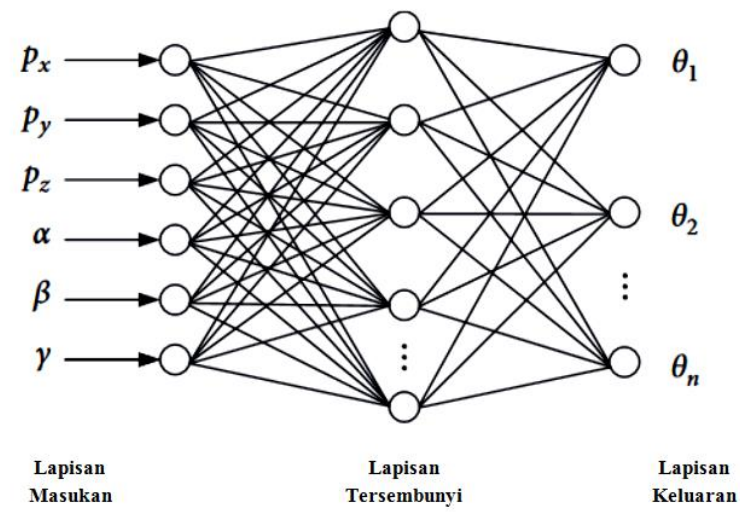

Gambar 2: Jaringan saraf RBF

Pada Gambar 2 menunjukkan diagram struktur dari jaringan saraf RBF manipulator dari n-dof [20]. Pada Gambar 2 tersebut diasumsikan bahwa masukan dari jaringan saraf RBF adalah posisi akhir pada variabel $x=\left[p_{x}, p_{y}, p_{z}, \alpha, \beta, \gamma\right]^{T}$, dan variabel keluaran adalah solusi invers dari robot lengan bahwa $n$ adalah sudut joint, $y=\left[\theta_{1}, \theta_{2}, \ldots, \theta_{j}, \ldots, \theta_{n}\right]^{T} \in R^{n}$, dimana y adalah vector dimensi ke $\mathrm{n}$, dan hubungan antara $\mathrm{x}$ dan $\mathrm{y}$ adalah:

$$
y_{n}=\sum_{i=1}^{k} \omega_{i j} \exp \left(-\frac{1}{2 \sigma^{2}}\left\|x_{k}-c_{i}\right\|^{2}\right), 2<n,
$$

Dimana

$$
\begin{aligned}
& x_{k}=\left[p_{x}^{k}, p_{y}^{k}, p_{z}^{k}, \alpha^{k}, \beta^{k}, \gamma^{k}\right]^{T}, \\
& c_{i}=\left[c_{1 i}, c_{2 i}, \ldots, c_{h i},\right],
\end{aligned}
$$

Dimana $x_{k}$ adalah parameter masukkan sampel k. $c_{i}$ adalah pusat simpul dari fungsi lapisan tersembunyi ke-i. h adalah jumlah simpul. $\omega_{i j}$ adalah bobot dari lapisan implisit ke lapisan keluaran. $y_{n}$ adalah keluaran sebenarnya dari sudut kebebasan ke-n. $\sigma$ adalah variasi dari fungsi lapisan tersembunyi.

Algoritma Koloni Semut Kuantum / Quantum Ant Colony Optimization Algorithm (QACA) adalah Sebuah sistem yang memungkinkan semua semut untuk menerapkan metode pengkodean bit kuantum dan pembaruan. Pada metode tersebut jumlah populasinya relative kecil, kinerja algoritmanya relative tinggi, dan tingkat konvergensinya cepat.

Dalam penelitian ini, jaringan saraf QACA dan RBF digabungkan untuk saling melengkapi satu sama lain dan memanfaatkan sepenuhnya kemampuan optimalisasi yang efisien dari koloni semut kuantum, dan langkah langkah peningkatan yang direncanakan untuk membentuk algoritma solusi invers dari mekanik robot lengan pada jaringan QACA-RBF. 


\section{Percobaan Simulasi dan Analisa Kesalahan dari Manipulator UR5}

Pada bagian ini terdiri dari dua sub bab yang membahas tentang algoritma prediksi dan kesalahan trajaktori gerakan dari metode yang digunakan.

\subsection{Pembentukan Permodelan Prediksi untuk Solusi Invers Robot Lengan UR5}

Pada bagian percobaan ini dilakukan dengan robot lengan UR5. Kemudian didapatkan secara acak 8000 titik disekitar robot lengan UR5 dan 1000 titik dipilih sebagai sampel pelatihan. Setelah normalisasi, parameter masukan dari jaringan RBF dibentuk, seperti $x=\left[p_{x}^{\prime}, p_{y}^{\prime}, p_{z}^{\prime}, \alpha^{\prime}, \beta^{\prime}, \gamma^{\prime}\right]^{T}$.

Sedangkan untuk mendapatkan parameter keluaran dari jaringan RBF, sudut joint harus dinormalisasi seperti $y=\left[\theta_{1}^{\prime}, \theta_{2}^{\prime}, \theta_{3}^{\prime}, \theta_{4}^{\prime}, \theta_{5}^{\prime}, \theta_{6}^{\prime}\right]$. Berdasarkan dari itu, maka prediksi model dari 6 masukan 6 keluaran dengan algoritma solusi invers berdasarkan jaringan QACA dibangun, pelatihan data pada permodelan prediksi berdasarkan pada 1000 titik yang sudah ditentukan sebelumnya.

\subsection{Analisa Kesalahan pada Trajektori Gerakan}

Pada Gambar 3 adalah end effector robot lengan UR5 yang disimulasikan dengan GAZEBO ROS. Untuk dapat menganalisa kesalahan trajektori pada kurva trajektori yang telah diketahui panjangnya dan dipilih secara merata 30 titik sebagai deskripsi trajektorinya. Posisi 30 titik tersebut dihitung menggunakan persamaan (1)-(4) untuk mendapatkan nilai $p_{x}, p_{y}, p_{z}, \alpha, \beta$, dan $\gamma$. Kemudian mendapatkan 30 set yang sesuai didapat dari hasil invers yang diketahui $\theta_{1}^{\prime}, \theta_{2}^{\prime}, \theta_{3}^{\prime}, \theta_{4}^{\prime}, \theta_{5}^{\prime}, \theta_{6}^{\prime}$, yang mana set tersebut akan digunakan sebagai titik referensi untuk analisis kesalahan trajektori. 30 titik yang sudah dipilih pada trajektori tersebut digunakan sebagai masukan. Setelah algoritma solusi invers berbasis pada jaringan QACA-RBF dihitung dan dinormalisasikan, maka nilai 30 set nilai keluaran yang diprediksi diperoleh. Untuk dapat mengevaluasi efek prediksi secara onjektif, maka digunakan indeks kesalahan absolut. 


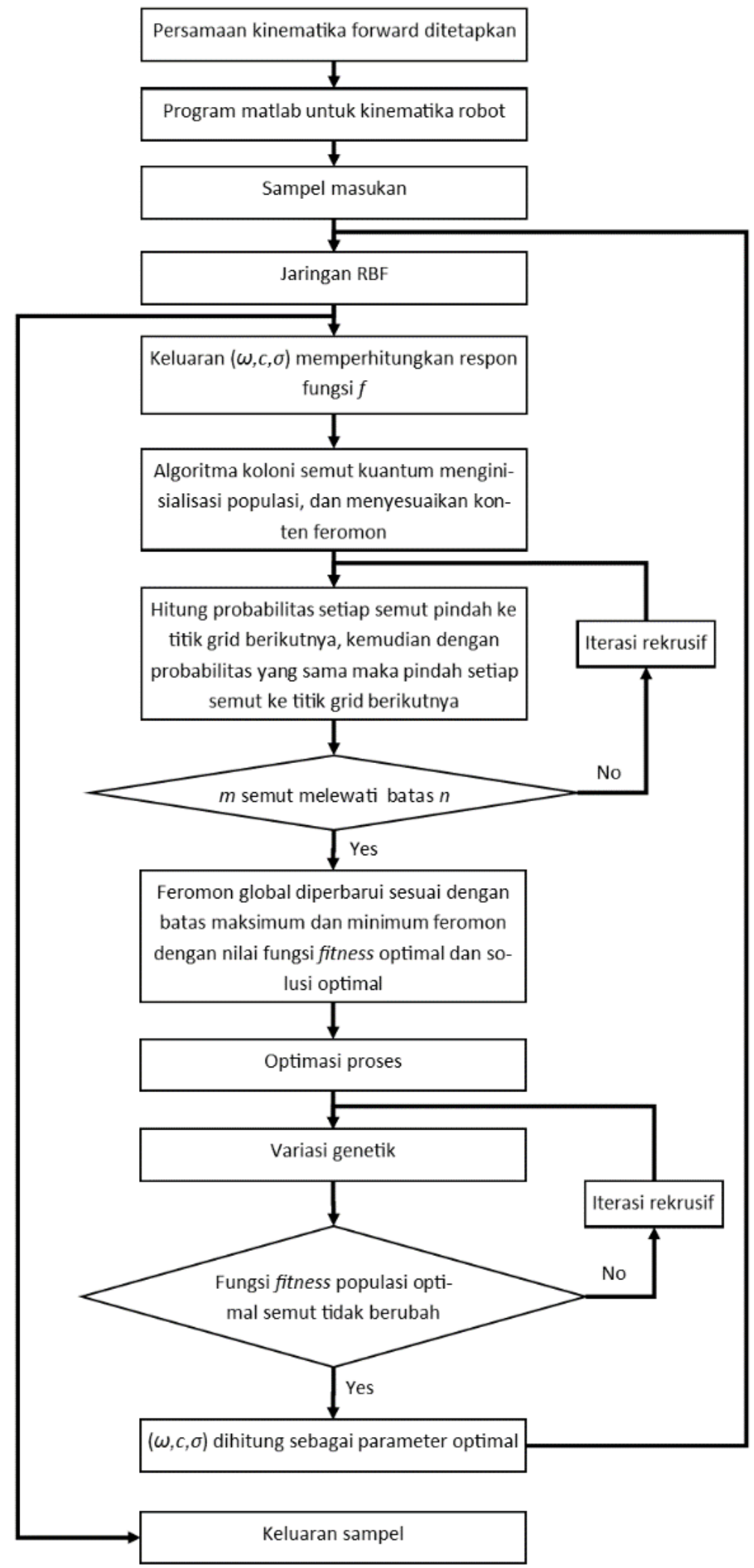

Gambar 2. Algoritma QACA-BRF untuk flowchart invers kinematic 


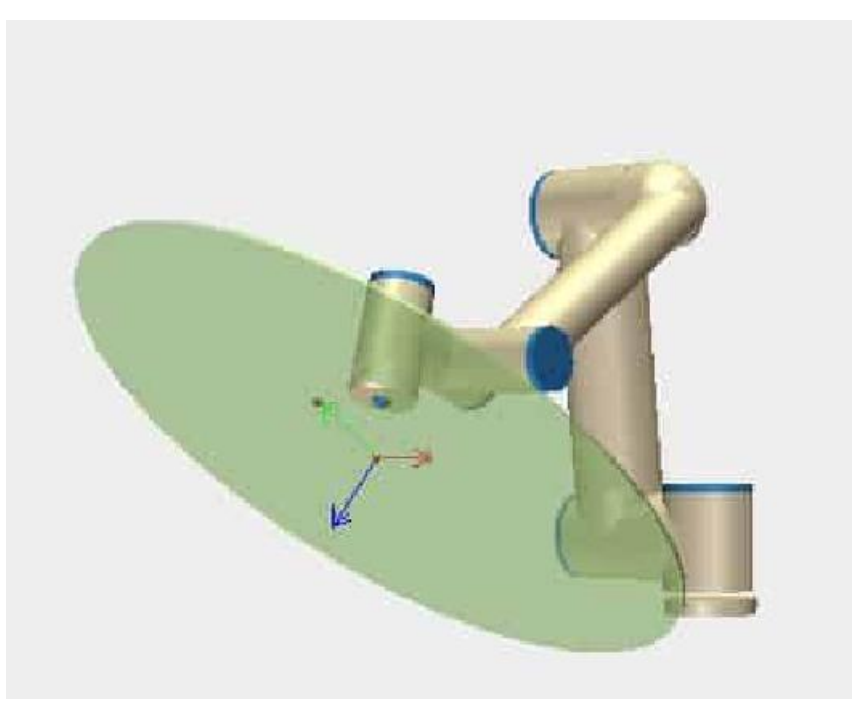

Gambar 3. End effector robot lengan UR5

Tabel 1. DH Parameter pada trajektori robot lengan

\begin{tabular}{ccccc}
\hline Joint i & $\boldsymbol{a}_{\boldsymbol{i}-\boldsymbol{n}}(\boldsymbol{m m})$ & $\boldsymbol{a}_{\boldsymbol{i}-\boldsymbol{n}}(\boldsymbol{m m})$ & $\boldsymbol{a}_{\boldsymbol{i}-\boldsymbol{n}}\left({ }^{\circ}\right)$ & $\boldsymbol{\Theta i}\left(^{\circ}\right)$ \\
\hline 1 & 0 & 0 & 0 & $-160 \sim 160$ \\
\hline 2 & 0 & 0 & -95 & $-225 \sim 45$ \\
\hline 3 & 10 & 3 & 0 & $-45 \sim 225$ \\
\hline 4 & 3 & 10 & -95 & $-110 \sim 170$ \\
\hline 5 & 0 & 0 & 95 & $-100 \sim 100$ \\
\hline 6 & 0 & 0 & -95 & $-266 \sim 266$ \\
\hline
\end{tabular}

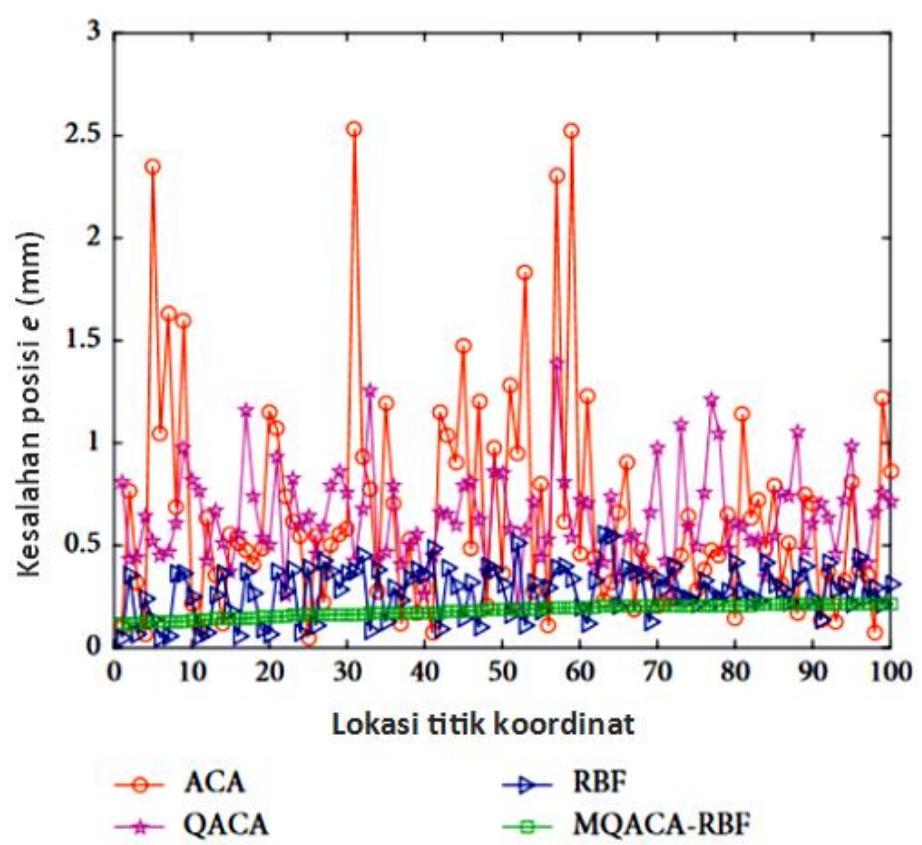

Gambar 5. Perbandingan kesalahan posisi ACA, QACA, RBF, QACA-RBF 
Pada gambar 7 dan 8 adalah nilai prediksi solusi invers dari 30 set dari sudut joint $\theta_{1}$ hingga ke $\theta_{6}$ yang sudah sesuai dengan 30 titik yang telah dipilihkemudian dibandingkan dengan kesalahan absolut nyatanya.

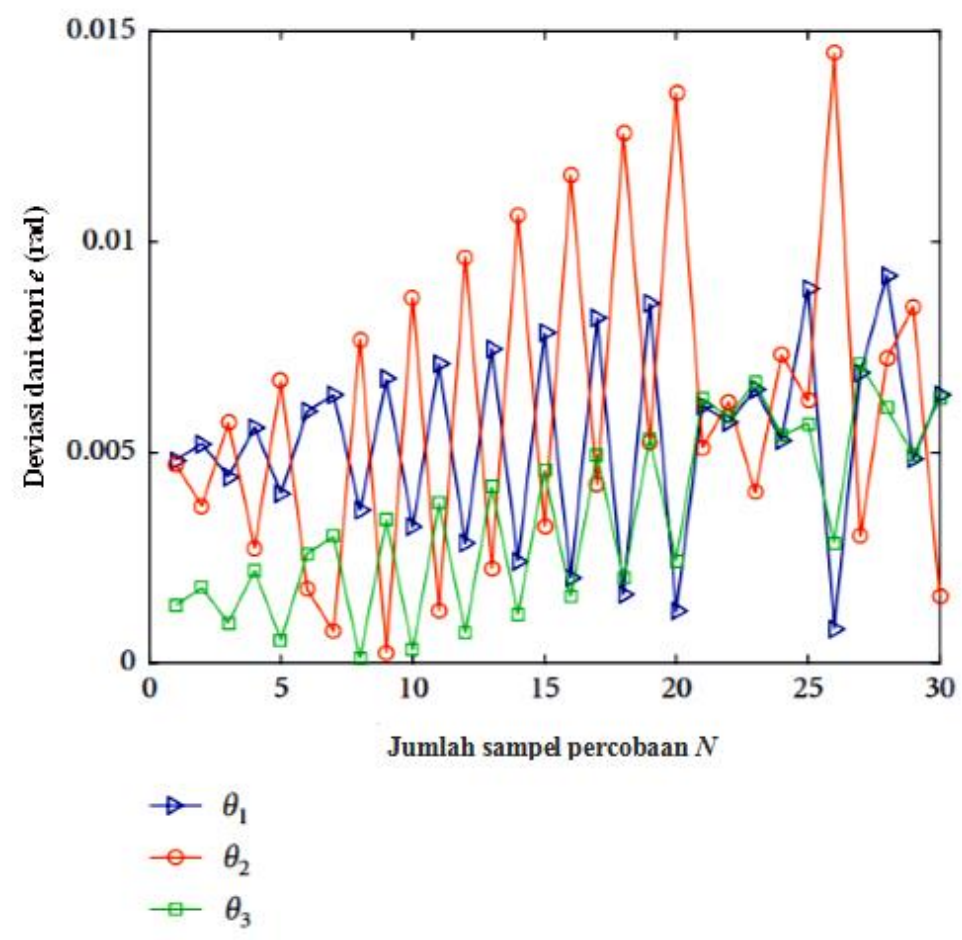

Gambar 7. Kesalahan absolut dari sudut joint $\theta_{1}, \theta_{2}$ dan $\theta_{3}$

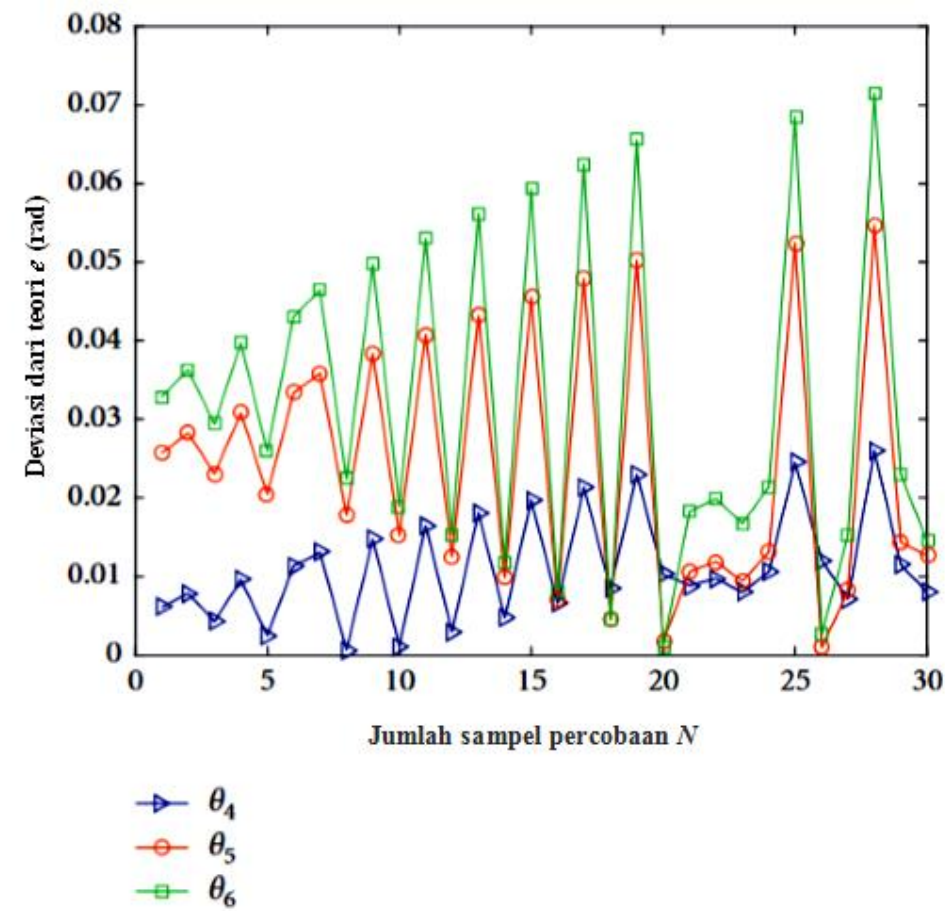

Gambar 8. Kesalahan absolut dari sudut joint $\theta_{4}, \theta_{5}$ dan $\theta_{6}$ 


\section{Kesimpulan}

Pada penelitian ini, manipulator yang menggunakan algoritma solusi invers yang didasari dengan jaringan QACA-RBF yang ditulis membuktikan bahwa metode ini efektif mencampurkan jaringan saraf RBF dan algoritma QACA. Metode tersebut juga memberikan keuntungan pada masing-masing algoritma. Kemudian dari percobaan simulasi trajektori dan simulasi kesalahan posisi membuktikan bahwa algoritma solusi invers menggunakan jaringan QACA-RBF lebih baik dibandingkan menggunakan algoritma solusi invers yang berbasis pada ACA, QACA, dan RBF karena kesalahan posisi masing-masing meningkat menjadi 3.89\%, 6.19\% dan $0.76 \%$.

\section{Referensi}

1. Venanzi, Stefano, and Vincenzo Parenti-Castelli. "A new technique for clearance influence analysis in spatial mechanisms." (2005): 446-455.

2. Pizzolato, C., et al. "Real-time inverse kinematics and inverse dynamics for lower limb applications using OpenSim." Computer methods in biomechanics and biomedical engineering 20.4 (2017): 436-445.

3. Ananthanarayanan, Hariharan, and Raúl Ordóñez. "Real-time inverse kinematics of redundant manipulator using a hybrid (analytical and numerical) method." 2013 16th International Conference on Advanced Robotics (ICAR). IEEE, 2013.

4. Schröder, Matthias, et al. "Real-time hand tracking using synergistic inverse kinematics." 2014 IEEE International Conference on Robotics and Automation (ICRA). IEEE, 2014.

5. Husty, Manfred L., Martin Pfurner, and Hans-Peter Schröcker. "A new and efficient algorithm for the inverse kinematics of a general serial 6R manipulator." Mechanism and machine theory 42.1 (2007): 66-81.

6. Kucuk, Serdar, and Zafer Bingul. "Inverse kinematics solutions for industrial robot manipulators with offset wrists." Applied Mathematical Modelling 38.7-8 (2014): 1983-1999.

7. Richter, Charles, Adam Bry, and Nicholas Roy. "Polynomial trajectory planning for aggressive quadrotor flight in dense indoor environments." Robotics Research. Springer, Cham, 2016. 649-666.

8. de Jesús Rubio, José, Enrique García, and Jaime Pacheco. "Trajectory planning and collisions detector for robotic arms." Neural Computing and Applications 21.8 (2012): 2105-2114.

9. Hao, Wong Guan, Yap Yee Leck, and Lim Chot Hun. "6-DOF PC-Based Robotic Arm (PC-ROBOARM) with efficient trajectory planning and speed control." 2011 4th International Conference on Mechatronics (ICOM). IEEE, 2011.

10. Antonelli, Gianluca, Stefano Chiaverini, and Giuseppe Fusco. "A new on-line algorithm for inverse kinematics of robot manipulators ensuring path tracking capability under joint limits." IEEE Transactions on Robotics and Automation 19.1 (2003): 162-167.

11. Bayro-Corrochano, Eduardo, and Julio Zamora-Esquivel. "Differential and inverse kinematics of robot devices using conformal geometric algebra." Robotica 25.1 (2007): 43-61.

12. Zamora-Esquivel, Julio, and Eduardo Bayro-Corrochano. "Robot perception and handling actions using the conformal geometric algebra framework." Advances in applied Clifford algebras 20.3-4 (2010): 959-990.

13. Pesonen, Janne, and Krister OE Henriksson. "Polymer conformations in internal (polyspherical) coordinates." Journal of computational chemistry 31.9 (2010): 1873-1881.

14. Tan, G. Z., and W. B. Li. "Design of ant algorithm-based optimal PID controller and its application to intelligent artificial leg." Zhongnan Daxue Xuebao(Ziran Kexue Ban)/J. Cent. South Univ.(Sci. Technol.)(China)(China) 35.1 (2004): 91-96.

15. Chen, Gang, et al. "Obstacle avoidance path planning of manipulator based on speed correction term." Control and Decision 1.30 (2015): 156-160.

16. Hong, Xie, et al. "Inverse kinematics solution method based on multi-subgroup hierarchical hybrid of differential algorithm and chaotic particle swarm optimization." Journal of Electronic Measurement and Instrumentation 10 (2015): 7.

17. Dash, K. K., et al. "A neural network based inverse kinematic problem." 2011 IEEE Recent Advances in Intelligent Computational Systems. IEEE, 2011. 
18. KöKer, RaşIt. "A genetic algorithm approach to a neural-network-based inverse kinematics solution of robotic manipulators based on error minimization." Information Sciences 222 (2013): 528-543.

19. Duka, Adrian-Vasile. "Neural network based inverse kinematics solution for trajectory tracking of a robotic arm." Procedia Technology 12.1 (2014): 20-27.

20. Pau, James WL, Shane SQ Xie, and Andrew J. Pullan. "Neuromuscular interfacing: Establishing an EMGdriven model for the human elbow joint." IEEE Transactions on biomedical engineering 59.9 (2012): 2586-2593.

21. Bin, He, Liu Wen Zhen, and Lv Hai Feng. "The kinematics model of a two-wheeled self-balancing autonomous mobile robot and its simulation." 2010 Second International Conference on Computer Engineering and Applications. Vol. 2. IEEE, 2010.

(C) 2019 by the authors. Submitted for possible open access publication under the terms and conditions of the Creative Commons Attribution (CC BY) license (http://creativecommons.org/licenses/by/4.0/). 